\title{
Translation and Linguistic Validation of a Swedish Study-Specific Questionnaire for Use among Norwegian Parents Who Lost a Child to Cancer
}

\author{
Hilde-Kristin Vegsund ${ }^{1,2, *}$, Toril Rannestad ${ }^{1}$, Trude Reinfjell ${ }^{2}$, Unni Karin Moksnes ${ }^{1}$, \\ Alexandra Eilegård Wallin ${ }^{3}$ and Mary-Elizabeth Bradley Eilertsen ${ }^{1}$ \\ 1 Department of Public Health and Nursing, Centre for Health Promotion Research, NTNU Norwegian \\ University of Science and Technology, Trondheim, 7491 NO, Norway; toril.rannestad@ntnu.no (T.R.); \\ unni.moksnes@ntnu.no (U.K.M.); mary-elizabeth.eilertsen@ntnu.no (M.-E.B.E.) \\ 2 Department of Psychology, NTNU Norwegian University of Science and Technology, Trondheim, 7491 NO, \\ Norway; trude.reinfjell@ntnu.no \\ 3 School of Education, Health and Society, Dalarna University, 79188 Falun, Sweden; aee@du.se \\ * Correspondence: hilde.k.vegsund@ntnu.no; Tel.: +47-73-41-2639
}

Received: 28 May 2018; Accepted: 1 October 2018; Published: 3 October 2018

\begin{abstract}
Background: Research is needed on how to help cancer-bereaved parents, as they are considered to be a vulnerable population and they are at risk of developing ill health following the loss of a child to cancer. The purpose of the present study was to translate and linguistically validate a Swedish study-specific questionnaire that was developed for Swedish cancer-bereaved parents. The translated questionnaire will be used in a nationwide study in Norway. Methods: Forward and backward translations of the Swedish study-specific questionnaire were conducted, followed by linguistic validation based on telephone interviews with six Norwegian cancer-bereaved parents. Result: It was found that several medical terms and conceptual issues were difficult for the Norwegian parents to understand. There were also four issues regarding the response alternatives. Conclusions: Although Sweden and Norway have quite similar cultures and languages, the results off this pilot study show that, to ensure the quality of a translated questionnaire, linguistic validation as well as translation is necessary.
\end{abstract}

Keywords: bereaved parents; childhood cancer; linguistic validation; pilot study; translation; vulnerable population

\section{Introduction}

Questionnaires that capture the essence of bereaved parents' experiences are needed to gather information about their psychological and social needs following the loss of a child. Parents have indicated that cultural aspects such as beliefs, values, and traditions need to be respected after the loss of a child. Parents also say that cultural preferences are individual and that religious practices should be performed in accordance with their own faith or their spiritual or religious beliefs (Meert et al. 2009). A long-term goal of this study is to begin to address the psychological and social needs of bereaved parents. A Swedish research group has developed a study-specific questionnaire to target the population of Swedish cancer-bereaved parents (Kreicbergs 2004). The Swedish study-specific questionnaire is frequently used and it has revealed important knowledge about Swedish bereaved parents' psychological health (Kreicbergs et al. 2004). Furthermore, knowledge about increased morbidity in fathers due to a limited awareness of their child's impending death add to the body of literature focusing on bereaved parents (Valdimarsdóttir et al. 2007). It has also been found that social support can decrease the negative long-term consequences of grief 
(Kreicbergs et al. 2007), and health-care services can decrease long-term distress among bereaved parents (Kreicbergs et al. 2005). The questionnaire has provided useful knowledge of Swedish parents' health-care experiences and of the parents' perception of their own health and well-being during a child's illness and following the loss. Therefore, this study-specific questionnaire has been translated into Norwegian for use in a nationwide study in Norway. Conducting surveys using the same instrument in different countries will facilitate comparisons of health outcomes in different countries and enable health-care professionals to target interventions that promote health and prevent illness among bereaved parents. In addition, the process of translating and linguistically validating an existing questionnaire can contribute to future cross-cultural studies that may also need to adapt pre-existing questionnaires. A study-specific questionnaire was needed, so that as many bereaved parents in Norway as possible can have the opportunity to tell their stories. Developing a new questionnaire is a time-consuming process; so translating and linguistically validating an existing questionnaire is a good option as long as the recommended methodological procedures are followed (Bricout 2017). To the authors' knowledge, this is the first time that a study-specific questionnaire for cancer-bereaved parents has been translated and linguistically validated from one language/culture to another. The translated Swedish questionnaire can contribute to knowledge about and the understanding of Norwegian cancer-bereaved parents' experiences after the loss of a child.

\section{Childhood Cancer}

After accidents, cancer is the second most common cause of death among children (McCarthy et al. 2010), and the loss of a child may be one of the most devastating events a parent can experience (Björk et al. 2016; Wender 2012). In the Nordic countries (Denmark, Finland, Iceland, Sweden, and Norway), cancer occurs in 18 children per 100,000 per year (Olsen et al. 2009). In Norway, approximately 190 children under the age of 17 are diagnosed with cancer each year (Dahlen et al. 2015). Improved treatments have reduced the death rate of childhood cancer. Today, about $20 \%$ of children diagnosed with cancer in Norway die, as compared to a death rate of $75 \%$ in the 1960s (Olsen et al. 2009). The incidence of childhood cancer in the USA is estimated to be 10,270 (for 0 - to 14 years-olds), and approximately 1,190 will die of the disease (Siegel et al. 2018). Even though more children diagnosed with cancer survive today than in the past, many parents still suffer the loss of their children each year, an event with enduring psychological sequelae. Norway has one of the highest five-year cancer survival rates in Western Europe (Gatta et al. 2014).

Bereaved parents are considered to be a particularly vulnerable group (Dyregrov 2004; Rubin and Malkinson 2001), and they report high prevalence of physical illness, such as disabilities, sleep disturbances (Stroebe et al. 2007), chest pain, and extensive use of prescriptive drugs (Murphy et al. 1999). In addition, parents who lose a child have a high risk of developing psychological problems, such as anxiety, depression (Barrera et al. 2007; Kreicbergs 2004; Lichtenthal et al. 2015), and prolonged grief (Lichtenthal et al. 2015; Van der Geest et al. 2014). These parents also have an increased risk of hospitalization due to mental illness (Li et al. 2005). Moreover, the loss of a child can increase parents' risk of mortality, especially in mothers. The mortality rate for mothers is highest in the three first years after they lost a child ( $\mathrm{Li}$ et al. 2003). The loss of a child may also affect the bereaved parents' relationship. However, findings on this topic are contradictory. One study found that bereaved parents experience higher divorce rates during the first six months after the loss than a non-bereaved control group (Najman et al. 1993). Another study found evidence for stronger bonds between bereaved parents post-loss if they openly communicated about their reactions to grief (Kamm and Vandenberg 2001). These findings are supported by Buyukcan-Tetik et al. (2017), who examined 229 bereaved parents and found that couples who had similar reactions to grief experienced a higher level of satisfaction in their relationships.

Over the last decades, numerous studies have been conducted among parents who have lost a child. However, most of these studies use qualitative interviews (Monterosso and Kristjanson 2008; Robert et al. 2012; Weidner et al. 2011). Other studies use mixed methods (Barrera et al. 2007; Bogensperger and Lueger-Schuster 2014) combining interviews or focus groups, with standardized 
scales that measure anxiety (Goodenough et al. 2004), depression (Barrera et al. 2007; Goodenough et al. 2004), grief (Barrera et al. 2007), or quality of life (Song et al. 2010). Even though such studies provide important information about bereaved parents' physical and psychological health, one limitation is the small number of participants, which makes it difficult to generalize the findings to the broader population of bereaved parents. The participants who will be included in this Norwegian national study lost a child to cancer between January 2009 and the end of December 2014. The death rate from childhood cancer in Norway is approximately $20 \%$, which corresponds to approximately 40 deaths annually. This means that the potential sample of Norwegian cancer-bereaved parents is around 450 informants. Therefore, a study-specific questionnaire is needed for a Norwegian national study of parents' perceptions of the health-care their children received, as well as their own physical and psychological health before and after their child's death.

\section{The Swedish Study-Specific Questionnaire}

The Swedish study-specific questionnaire was developed based on a literature review, contributions from experts in the field, and in-depth interviews with seven cancer-bereaved parents. These interviews were focused on the parents' experiences of having a child diagnosed with cancer. The parents were asked to describe how they perceived the illness period and the following loss (Kreicbergs 2004). Another 15 interviews were conducted with cancer-bereaved parents to ensure that the questionnaire was understood as intended, indicating face validity. In addition, descriptive analysis that measured the means of the questions were conducted in a pilot study with another 22 bereaved parents, resulting in adjustment of the questionnaire (Jalmsell 2015; Kreicbergs 2004). The data gathered from the Swedish cancer-bereaved parents has resulted in four doctoral dissertations (Jalmsell 2015; Kreicbergs 2004; Lannen 2008; Surkan 2006). Several other studies have been conducted based on parental responses to this questionnaire; Hunt et al. (2006) found that the loss of a child's ability to communicate as well as a prolonged illness period increased the probability of parents indicating that death would be the best outcome for the child. Lannen et al. (2008) found evidence for an increased risk of long-term mental distress (anxiety, depression, and low quality of life) and physical morbidity (sleep deprivation) among parents who had not processed their grief over a child's death. Surkan et al. (2006) found an association between bereaved parents' perceptions of inadequate health care and feelings of guilt after the loss of a child. Another study found that social support from health-care professionals, family members, or friends following the loss played a significant role in helping parents to work through their grief (Kreicbergs et al. 2007).

The Swedish study-specific questionnaire is divided into six main sections that cover different time-spans during the child's illness and after death. It consists of 104 questions and 202 items (Table 1). The items are follow-up questions or spaces for additional comments. Most of the questions and the response alternatives use lay language, only a few medical terms are used. All of the items are categorical, and the questions have two to ten response alternatives. Some questions have two response alternatives, such as: "Did you see your child regularly during her/his illness period?" The response alternatives for this question are "Yes" and "No". Other questions have up to ten response alternatives, such as: "How were you informed about your child's cancer diagnosis?" The response alternatives for the question are: "In a conversation with the child and the child's other parent"; "In a conversation without the child but with the child's other parent"; "In a conversation with the child but without the child's other parent"; "In a conversation without the child and without the child's other parent"; "In a conversation with the child's other parent"; "In a conversation with the child"; "By telephone"; "By letter"; "Other"; and "Not relevant, I was never informed". This question also has a follow-up item: "Who informed you of your child's illness?" The response alternatives for this item are: "A doctor"; "A nurse"; and, "Other, who"? The questionnaire also has several open-ended items that allow the parents to make comments and tell their personal stories about their experiences during their child's illness and following the loss. An example of a question with open-ended items is: "Have your personal or spiritual/religious beliefs been affected by the loss of your child?" The response 
alternatives are: "Not relevant, I do not have personal or spiritual/religious beliefs"; "Yes, a little"; "Yes, some"; "Yes, a lot". The follow-up items are: "Have your personal or spiritual/religious beliefs been positively affected? Please comment" and "Have your personal or spiritual/religious belief been negatively affected? Please comment". Sufficient space is then provided for comments.

Table 1. Content of the Swedish Study-Specific Questionnaire.

\begin{tabular}{|c|c|c|}
\hline Main Sections $* 1$ & Questions *2 & Content Summary \\
\hline $\begin{array}{l}\text { Questions about you } \\
\text { and your life situation } \\
\text { at the time your child } \\
\text { got sick }\end{array}$ & $\begin{array}{l}14 \text { questions } \\
\text { (15 items) }\end{array}$ & $\begin{array}{l}\text { Family situation at the time the child was diagnosed with } \\
\text { cancer (e.g., gender, age, marital status, total number of } \\
\text { children) } \\
\text { Child's age at the time of the diagnosis } \\
\text { Whether the parents lived together and with the child at the } \\
\text { time of diagnosis }\end{array}$ \\
\hline $\begin{array}{l}\text { How you and your } \\
\text { child received the } \\
\text { message about the } \\
\text { cancer illness }\end{array}$ & $\begin{array}{l}15 \text { questions } \\
\text { (27 items) }\end{array}$ & $\begin{array}{l}\text { How the child was informed about the diagnosis (e.g., if the } \\
\text { child was with one or both parents, without either parents, or } \\
\text { if they were never informed). There is also a follow-up item } \\
\text { asking who informed the child. } \\
\text { How the parents were informed about the diagnosis (see } \\
\text { example above) } \\
\text { Whether the cancer disease was curable } \\
\text { Whether the parents were satisfied with the information they } \\
\text { received from health care professionals }\end{array}$ \\
\hline $\begin{array}{l}\text { Your child's last month } \\
\text { of life }\end{array}$ & $\begin{array}{l}12 \text { questions } \\
\text { (56 items) }\end{array}$ & $\begin{array}{l}\text { Parents' experiences with the health care provided (pain relief, } \\
\text { treatment of depression/anxiety) } \\
\text { Communication with the child } \\
\text { Whether the parents received the support they needed }\end{array}$ \\
\hline $\begin{array}{l}\text { Insight into your } \\
\text { child's death and } \\
\text { conversation about } \\
\text { death }\end{array}$ & $\begin{array}{l}29 \text { questions } \\
\text { (48 items) }\end{array}$ & $\begin{array}{l}\text { If and when the parents understood that their child was going } \\
\text { to die } \\
\text { If the child understood that he/she was going to die } \\
\text { Conversations about death with the child } \\
\text { Conversations about death with family/friends/health care } \\
\text { professionals }\end{array}$ \\
\hline $\begin{array}{l}\text { The time after your } \\
\text { child died }\end{array}$ & $\begin{array}{l}\text { Eight questions } \\
\text { (22 items) }\end{array}$ & $\begin{array}{l}\text { Follow-up and conversations with the health care personnel } \\
\text { treating the child } \\
\text { The time-span of these conversations } \\
\text { A retrospective view of the health care their child received } \\
\text { during their illness period }\end{array}$ \\
\hline $\begin{array}{l}\text { You and your current } \\
\text { life situation }\end{array}$ & $\begin{array}{l}26 \text { questions } \\
\text { (34 items) }\end{array}$ & $\begin{array}{l}\text { Sociodemographic questions } \\
\text { Whether the parents religious beliefs was affected by their } \\
\text { child's death } \\
\text { Social support } \\
\text { Adjustment to the loss } \\
\text { Items about how they experienced to fill out the questionnaire }\end{array}$ \\
\hline
\end{tabular}

Note: ${ }^{* 1}$ The main sections include three time-spans during the child's illness period, the time of death, and the time after death. ${ }^{* 2}$ Some questions include follow-up questions or space for personalized comments, these are called as items in this questionnaire.

\subsection{Instrument Equivalence}

A thorough translation is important and ensures that a translated instrument is equivalent to the original version. Cross-cultural research involves unique methodological issues most of which have to do with the translation of questionnaires (Sperber 2004). In addition, translated questionnaire must be adapted to the new culture and target group while preserving the equivalence of content between the original questionnaire and the translated version (Beaton et al. 2000; Sperber 2004). Conceptual equivalence is ensured through the translation process and through interviews that test the formulation of the questions and the response choices (Quittner et al. 2000; Wild et al. 2005). One way of ensuring conceptual equivalence is back-translation by two independent blinded translators (Sperber 2004); this procedure was used in the present study. Back-translation results in two translations that may 
be compared to identify differences in word choice and phrases that may be difficult for participants to understand.

Linguistic validation was also used in this study. This is a process (U.S. Department of Health and Human Services Food and Drug Administration 2009) in which, in this case, the translated questions and response alternatives are actively tested with the target population, in the target language, through cognitive debriefing. Cognitive debriefing provides an overview of the respondents' comprehension and interpretation of the translated questionnaire, as well as their impression of its relevance. The goal of these interviews were to ensure that the translated questions and response alternatives were understood as intended (Bice and Kalimo 1971). In this study, respondents were interviewed to measure their understanding of the questionnaire, and the questions and response alternatives that the informants found difficult were changed. By conducting further interviews, the validation may be confirmed by ensuring terms are not interpreted differently by different informants (U.S. Department of Health and Human Services Food and Drug Administration 2009).

Before the translation process in the present study was begun, it was expected that the Swedish study-specific questionnaire would not need major revisions, since the Nordic countries are quite similar culturally and linguistically (both written and spoken). However, some words that are pronounced or written alike can have a different denotation. To ensure the quality and relevance of the instrument and to ensure that respondents understood the questionnaire, we conducted a linguistic validation of the translated study-specific questionnaire. According to Wild and colleagues, translation from, for example, Russian to English (called "language to language" translation) is approached differently than "same language adaptations" (Wild et al. 2005, p. 95), such as English in the UK translated for use in the United States. Since Swedish and Norwegian are comparable languages with only slight differences, we decided to conduct the translation process and linguistic validation less strictly than recommended if the translation were from English to Norwegian.

\subsection{Purpose}

The purpose of the present study was to translate the Swedish study-specific questionnaire on the experiences of parents who have lost a child to cancer into Norwegian and to conduct a linguistic validation of the Norwegian translation.

More specifically, the focus of the interviews was to assess:

- whether the questions were understood as intended,

- whether the range of response alternatives was adequate, and

- whether there were any conceptual issues with the translation of the Swedish study-specific questionnaire.

\section{Materials and Methods}

\subsection{Translation and Linguistic Validation of the Study-Specific Questionnaire}

The questionnaire was translated (Figure 1) according to guidelines for multicultural translation procedures (Sperber 2004; WHO n.d.; Wild et al. 2005) and according to the recommendations of several investigators (Beaton et al. 2000; Eremenco et al. 2005; Quittner et al. 2000; Sperber et al. 1994).

The study-specific questionnaire was first translated from Swedish to Norwegian (target language) by two independent native Norwegians who worked at a Norwegian university as consultants and were well acquainted with the Swedish language (source language). The research team read the interviews and identified questions and response alternatives that the informants found difficult. Changes were made after the researchers discussed the issues and agreed on revised questions. After the two translations were revised, the research team created a Norwegian draft. Two bilingual Swedish individuals who had lived in Norway for several years and who spoke Norwegian fluently back-translated the study-specific questionnaire into Swedish. The back-translated versions were then compared to the Swedish original version. A final draft of the study-specific questionnaire was then 
created based on a consensus in the Norwegian research group. At the end of 2016, the Norwegian version of the study-specific questionnaire was ready for a qualitative linguistic validation.

Step 1

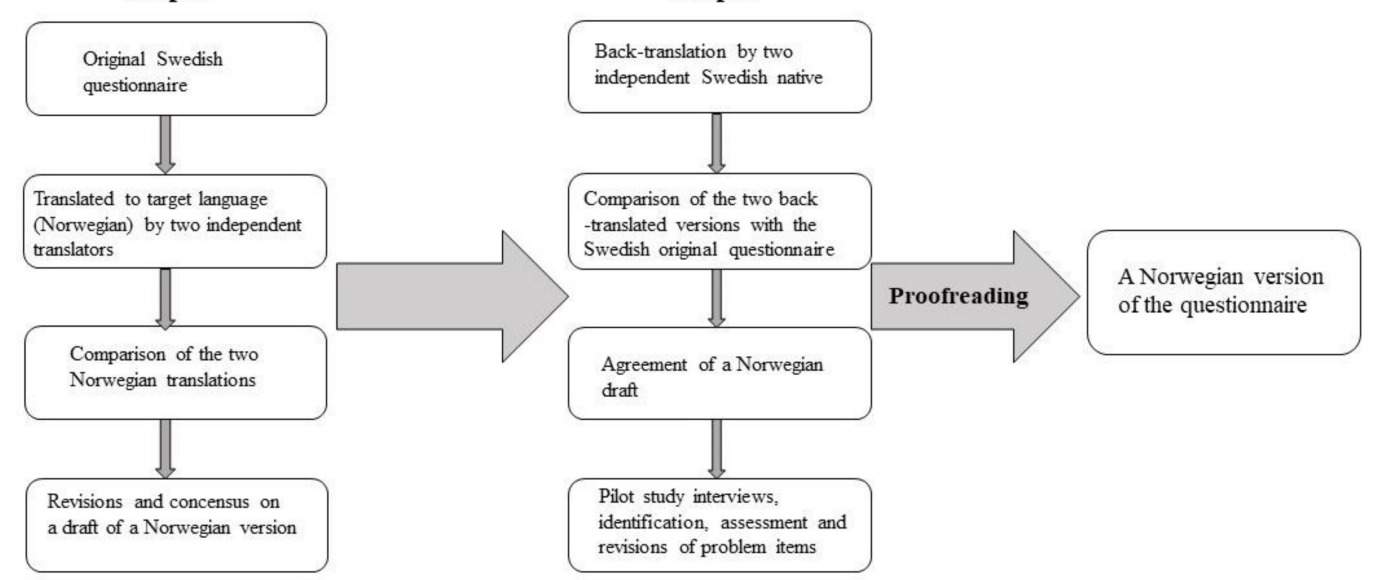

Figure 1. Translation process of the Swedish study-specific questionnaire.

\subsection{Participants}

Eighty-nine children who died between 2007 and 2008, were identified through the Cancer Registry of Norway and the Norwegian Cause of Death Registry. The Norwegian National Registry identified 170 bereaved parents; twelve of these were sent an information letter describing the purpose of the study; it also included a written consent form for participation. The letter emphasized the voluntary nature of participation and stipulated that consent could be withdrawn without reason. Because of the very low response rate from the twelve parents $(n=1)$, which is usual with vulnerable groups, such as parents after the loss of a child (Stevens et al. 2010), the ethical committee gave their consent for the Norwegian Children's Cancer Society to contact parents directly and then refer them to our research group. Six parents were contacted, all of whom agreed to participate and provided written consent. One participant later withdrew their consent and also declined an offer of follow-up from the research team, indicating that there was no need for follow-up. No data were received from the participant who withdrew, so this participant was not included in analysis. The informants received the questionnaire as a hard copy by post approximately two weeks before the interviews took place. The interviewer (first author) had ongoing contact with the informants; this researcher distributed the information letter and the questionnaire, answered questions, and scheduled the interview appointments. Four bereaved mothers and two bereaved fathers completed telephone interviews. The participants came from different regions of Norway, but none came from the northern part of Norway. However, the participating parents had experience with different university hospitals, treatment institutions, and/or local hospitals.

\subsection{Procedure}

When the appointment for the interview with the first informant was scheduled, the informant requested to conduct it as a telephone interview. The reason for the request was the sensitive nature of the topics; the participant indicated that it would be more difficult for them to meet face to face for the interview than over the telephone. Consequently, all of the interviews were completed by telephone during the winter of 2016/2017. Each participants chose a location where they could speak freely and not be disturbed, and the interviews were scheduled at a time convenient for them. The interviews were recorded and lasted for 60 to $90 \mathrm{~min}$. The duration of each interviews was adjusted as needed to address all of the items in the questionnaire. The interviewer transcribed the interviews.

The focus for the interviews was to probe the questions and response alternatives in the translated study-specific questionnaire. All participants were asked if they understood the intention of the 
interviews, namely to ensure the quality of the translated questionnaire. All the items except those items addressing sociodemographic factors and open-ended items were explored with enquiries about the questions and the response alternatives, such as; "How do you understand this question?" and "Is it possible for you to mark any of the response alternatives?" The informants were also asked to comment on words, questions, or response alternatives that they found difficult to understand or respond to. In addition, the informants answered each item, and their responses indicated whether or not they understood the questions and whether the response alternatives were appropriate. There were several spaces for personalized comments throughout the questionnaire and the informants were asked if they wanted or needed to add anything in these comment spaces. At the end of each interview, the informants were asked if they thought the questionnaire left out any questions or topics, or if they had anything to add. One question, with a follow-up item and an open-ended item were added into the questionnaire based on these responses (Table 2).

Table 2. Issues and modifications revealed after interviews.

\begin{tabular}{|c|c|}
\hline Issues with Medical Terms & Modifications \\
\hline $\begin{array}{l}\text { "Did your child } \\
\text { after the illness }\end{array}$ & "Did your child's cancer disease reoccur (relapse) after he/she \\
\hline child died was curative & $\begin{array}{l}\text { "How long before your child died was curative treatment for } \\
\text { your child's cancer disease discontinued?" }\end{array}$ \\
\hline $\begin{array}{l}\text { "Was the illness the direct cause of your child's } \\
\text { death, or was death due to complications } \\
\text { caused by treatment?" }\end{array}$ & $\begin{array}{l}\text { "Was the cancer disease the direct cause of your child's death, or } \\
\text { was it due to complications caused by the treatment?" }\end{array}$ \\
\hline Conceptual & Modific \\
\hline $\begin{array}{l}\text { "Do y } \\
\text { they } \mathrm{r}\end{array}$ & $\begin{array}{l}\text { "Do you think doctors should be explicit with the parents when } \\
\text { they realise that the disease cannot be cured?" }\end{array}$ \\
\hline $\begin{array}{l}\text { k with your child about topics } \\
\text { important during your child's }\end{array}$ & $\begin{array}{l}\text { "Could } \\
\text { importa }\end{array}$ \\
\hline $\begin{array}{l}\text { e professionals reacted quickly if } \\
\text { eeded help". }\end{array}$ & rofessionals reacted quickly if my child \\
\hline Issue & Mod \\
\hline $\begin{array}{l}\text { Ques } \\
\text { trans }\end{array}$ & t?" \\
\hline $\begin{array}{l}\text { ild did not receive a bone marrow } \\
\text { e had bone marrow transplant with }\end{array}$ & $\begin{array}{l}\text { "No, my child did not receive a bone marrow transplant". } \\
\text { "Yes, he/she had bone marrow transplant with his/her own } \\
\text { bone marrow". }\end{array}$ \\
\hline his/h & "Yes, he/she had bone marrow transplant with a donor's bone \\
\hline $\begin{array}{l}\text { larrow transplant with } \\
\text { le bone marrow } \\
\text { s". }\end{array}$ & $\begin{array}{l}\text { "Please, comment". Space for personal comments was added in } \\
\text { the questionnaire. }\end{array}$ \\
\hline $\begin{array}{l}\text { Question: "Did you receive any social support } \\
\text { to help you deal with your emotions and the } \\
\text { situation in general during your child's illness }\end{array}$ & $\begin{array}{l}\text { Question: "Did you receive any social support to help you deal } \\
\text { with your emotions and the situation in general during your } \\
\text { child's illness period?" }\end{array}$ \\
\hline $\begin{array}{l}\text { "From health-care personnel"; "From family, } \\
\text { relatives and friends"; "Other, who?" The } \\
\text { response alternatives are: "No, not at all"; "Yes } \\
\text { some"; "Yes, enough"; "Yes, a lot". }\end{array}$ & $\begin{array}{l}\text { "From health-care personnel"; "From family, relatives and } \\
\text { friends"; "Other, who?" The response alternatives were revised } \\
\text { to: "No, not at all"; "Yes some"; "Yes, enough"; "Yes, a lot": and } \\
\text { "Not relevant, I did not need social support". }\end{array}$ \\
\hline $\begin{array}{l}\text { Question: "Do you think you have processed } \\
\text { your grief?" }\end{array}$ & \\
\hline $\begin{array}{l}\text { all"; "Yes, a little"; "Yes, fairly } \\
\text { d"Yes, completely". }\end{array}$ & a nute, res, raming mucnt. \\
\hline $\begin{array}{l}\text { Question: "Have your personal or } \\
\text { spiritual/religious beliefs been affected by the } \\
\text { loss of your child?" } \\
\text { The response alternatives are: "Not relevant, I } \\
\text { do not have a spiritual/religious beliefs", "Yes, } \\
\text { some"; "Yes, to a certain degree"; "Yes, a lot". }\end{array}$ & $\begin{array}{l}\text { Question: "Have your personal or spiritual/religious beliefs } \\
\text { been affected by the loss of your child?" } \\
\text { The response alternatives are revised to: "No"; "Not relevant, I } \\
\text { do not have a spiritual/religious beliefs"; "Yes, some"; "Yes, to a } \\
\text { certain degree"; "Yes, a lot". }\end{array}$ \\
\hline
\end{tabular}


Table 2. Cont.

\begin{tabular}{ll}
\hline \multicolumn{1}{c}{ Issues with Medical Terms } & \multicolumn{1}{c}{ Modifications } \\
\hline & $\begin{array}{l}\text { Question added } \\
\text { Question: "Have your received any help/follow-up from your } \\
\text { municipality to help you in your grief process after your child's } \\
\text { death? From whom?" }\end{array}$ \\
$\begin{array}{l}\text { Response alternatives: "GP"; "Psychiatric nurse in your } \\
\text { lack of follow-up in the municipalities after the } \\
\text { child died }\end{array}$ & $\begin{array}{l}\text { "Bunicipality"; "Psychologist"; "Home nursing care"; } \\
\text { "Bereavement group"; "Voluntary/humanitarian organization"; }\end{array}$ \\
& $\begin{array}{l}\text { "Religious community"; "Other: } \\
\text { Follow-up item: "Did you find the help from the municipality } \\
\text { useful": "Yes/No". } \\
\text { ""Please comment": Space was added for personal comments. }\end{array}$ \\
\hline
\end{tabular}

\subsection{Data Analyses}

All of the interviews were recorded, and the interviewer transcribed all six interviews immediately after completing the interviews. The members of the research team read the interviews separately and made individual comments about the items, questions, response alternatives, and other comments made by the informants. The research group then held three meetings to analyze and discuss the findings of the interviews and the issues they revealed. The meetings took place after the first interview, after the fourth interview, and after the sixth interview. Comments on the questions, response alternatives, and items were analyzed. Changes were made based on difficulties the bereaved parents had in understanding the questionnaire; either it was questions or response alternatives. The following steps were taken:

1. The research team independently analyzed the transcribed interviews, looking for parents' comments about their understanding of questions, items, and response alternatives. The researchers also looked for words or phrases the informants found upsetting or negative in any way. At the end of each interview, the informants were asked if the questionnaire failed to address any important topics that were related to their experience of having a child with cancer who died of the disease.

2. After a discussion of the problematic issues, a Norwegian draft was made. The Norwegian draft was then compared to the Swedish version of the questionnaire. The research group evaluated the issues and made necessary adjustments to the questions, response alternatives, and/or items to achieve the best possible fit for a Norwegian population of bereaved parents.

3. These two steps were repeated three times, after the first, fourth, and sixth interviews. After the sixth interview, a final version of the translated Norwegian study-specific questionnaire were made.

\subsection{Ethics}

The Regional Committee for Medical and Health Research Ethics (Ref. 2014/1997/REK Midt) approved the study. The ethical concern in bereavement studies is the risk of inflicting harm on bereaved parents by inviting them to fill out a questionnaire about to their loss. To get approval from the ethical committee, we had to establish a follow-up team within the research group. The team included a pediatric oncologist, a clinical psychologist, a research oncology nurse, and an experienced clinical nurse who would assist the participants if they experienced any psychological distress due to their participation in the study. If an informant in need of psychological follow-up contacted the research team, then the team would contact health-care professionals in the informant's primary care community. This was done to ensure that the participants' health and well-being were taken care of and that they would receive any necessary assistance from health-care professionals. All six informants were asked if they had been adversely affected by filling out the questionnaire or participating in the interview. They indicated that they considered it to be a positive experience to have the opportunity 
to help other bereaved parents. However, they also pointed out that the questionnaire is extensive, and they indicated that some of the questions were difficult for them to answer. All six participants declined follow-up after the interview.

The participants were also informed orally after the interview and also in writing that they could contact the research group by telephone or e-mail at any time during the entire study period. The research group's email addresses and telephone numbers were listed in the information letter and on the last page of the questionnaire. However, none of the informants contacted anyone in the research team after the interviews were completed.

\section{Results}

The findings of the interviews indicated that the questions and response alternatives in this Swedish study-specific questionnaire are appropriate for Norwegian cancer-bereaved parents. The parents indicated that the questionnaire covered the topics that were relevant to their experiences from the time of their child's diagnosis to the time of the interview, including how the loss of a child affected their physical and psychological health. None of the parents indicated that they had difficulties understanding the main sections covering the different time-spans defined in the study-specific questionnaire (Table 1). However, some did express issues with a few medical terms, conceptual issues, and response alternatives (Table 2).

\subsection{Issues with Medical Terminology}

The first qualitative interviews revealed some minor issues regarding medical terms. Throughout the Swedish questionnaire, the word illness was used referring to cancer. Some of the Norwegian informants indicated during the interviews that they wondered about the meaning of the word illness. In some cases, "illness" was misinterpreted as referring to symptoms e.g., epileptic seizure because of a brain tumor. One informant stated, "My child was well for a period of time, and then it (epilepsy) came back, and my child became gradually more ill, started with treatment and then became better again ...... so this is bit difficult to answer". When the parent was told the question refers to the child's cancer diagnosis, they responded, "OK, then it makes more sense". The word "illness" was also misunderstood in a question that asked parents whether curative treatment of their child's illness was discontinued before death. Some informants asked whether this meant that treatment with steroids, antibiotics, blood transfusion, etc. had ended, and not only active treatment of the cancer. Therefore, all of the questions in which "illness" was misinterpreted, illness was rephrased to "cancer disease" (Table 2). After changing the question by replacing the word "illness" with "cancer disease", it was then clear to the informants that these questions addressed the cancer rather than any sequelae of the cancer or side effects of treatment.

The question about whether cancer had relapsed after the child had been declared healthy was also problematic for some informants. "Relapse" was misinterpreted as referring to symptoms, such as infections because of a low level of leucocytes due to chemotherapy. The phrasing of the question was, therefore, changed to ask directly whether the cancer disease had come back, with relapse in brackets (Table 2). This clarification solved this problem.

\subsection{Conceptual Issues}

The interviews also revealed three conceptual issues. One question that caused difficulties for the parents was the one that asked whether the parents thought that doctors should be explicit when they realised that the disease could not be cured. Informants asked, "Explicit with whom?" It was added "towards the parents" to clarify that it was information from the doctors to the parents rather than information to colleagues or the child.

Another question that appeared to be problematic was the one that asked whether parents could talk with their child about topics that they considered to be important. The original question was: "Could you talk with your child about what you considered important during their illness period?" 
Several parents wondered if "important" meant talking about death, but that particular question was asked later in the questionnaire. One parent commented, "Talk about important things ... ... a little later it is asked if you told your child that he/she was going to die ... ... I was unsure if the question was about that". Another response about the same question was: "I do not quite get the question $\ldots . .$. is it an existential question? ... ... I'm thinking it is important to take care of each other, to do things ........ like it used to be, you know". The question was therefore, changed to "Could you talk with your child about what you considered important 'there and then' during their illness period?" This change was intended to clarify that the question addresses topics that were important for the parents and children in their everyday life (Table 2).

Another issue was related to whether health care staff reacted quickly if the child or the parents needed help. Two of the parents pointed out that there was a significant difference between a parent needing help and a sick child needing help. Consequently " $\mathrm{I}^{\prime}$ (referring to the parent) was removed from the question (Table 2). One parent said; "If the question were phrased; the health care staff reacted quickly if your child needed help, I would answer "to a great extent", but here you ask if I or my child ... . then I would answer "to a certain extent", because I needed help, but I didn't get the help I needed".

\subsection{Issues with Response Alternatives}

A few issues regarding the response alternatives were also discovered. There were three response to a question whether or not their child had a bone marrow transplant; "Yes, with own bone marrow", "Yes, with someone else's bone marrow" and "Yes, several times". One parent said; "If you answer; "Yes, with his/her own bone marrow", then you can't answer; "Yes, several times" ... ... and the same with a donor's bone marrow transplant". The response alternative "Yes, several times" was removed because it excluded the two first response options. A comment field was added for parents to provide further information (Table 2).

Another question asked parents if they thought they had processed their grief. The original response alternatives were "No, not at all", "Yes, to some extent", "Yes, to a great extent", and "Yes, completely". During the interviews, several parents said that it was impossible to process the grief completely, and that they had negative reactions to this phrasing. One parent said; "Totally ... ? I don't think so ... . . I I don't believe anyone can answer that ... ..." Another parent said: "One never gets over it ... ... I know some parents who would be really furious about that response option". As a consequence, the response alternative "Yes, completely" was removed (Table 2).

In the Swedish questionnaire, several items ask whether the parents received the social support they needed and whom they could talk to during their child's illness period and following the loss. The response alternatives included family members, friends, and neighbors. One informant indicated that there should be a response alternative for those who did not need extra support or someone to talk to. One informant said: "I didn't need or want any support . . . . , so it was difficult for me to find a proper response to that question". As a result, the response alternative "I did not need social support/someone to talk to" was added (Table 2).

The last issue with the response alternatives was found in the question asking whether the loss of their child affected the parents' religious beliefs. The original questionnaire did not include "No" as a response alternative. The parents pointed out that a participant could be religious, but their beliefs could be unaffected by the loss. Consequently, a "No" (Table 2) response alternative for this question was added to the final version of the Norwegian study-specific questionnaire.

\subsection{Need for Extra Questions}

At the end of the interviews, an iterative topic that was discussed by parents was the importance of follow-up in their home community after their child's death. Some informants indicated that they had received insufficient follow-up from health-care professionals, their GP, or voluntary organizations in their home community after their child's death. However, the informants who were satisfied with 
their own follow-up said that they knew other bereaved parents who needed more support from professionals or other groups working with grieving parents. One informant said: "We were well taken care of at the hospital, but after the death of our child, and you are at home, then it is ...... quiet ... . . . ..and then it depends on the community ..... Some don't have the energy to reach out for help ... ..my point is that maybe the hospitals should be better at ... .or those caring for the child during the last month ....... they should have some connection to the community". Another said; "When a child dies in an accident or something unforeseen happens, there is often a notice in the local newspaper or in the media ... ...and then the community's support network is there ... ... You can ask yourself ... is one death worth more to society than another? Why do you get help when your child dies because of one thing, but not if they die from something else?" Therefore, a question was added to ask whether the parents received follow-up care from community health-care services, as well as from voluntary organizations or religious community after their child's death (Table 2). Parents were also asked if they considered the follow-up care at the hospital and their community health-care services satisfactory. Space for personal comments was also added here.

\section{Discussion}

The purpose of the present study was to translate and linguistically validate a Swedish study-specific questionnaire regarding the experiences of parents who have lost a child to cancer. To the authors' knowledge, this is the first questionnaire of its kind for cancer-bereaved parents in Norway. Overall, the parents indicated that the study-specific questionnaire was relevant for their assessment of the health-care and follow-up during their child's illness period and after their child's death. As anticipated, there were no major concerns regarding the study-specific questionnaire. The questionnaire was easily understood, and most of the questions had adequate response alternatives, indicating face validity. No questions or items were removed from the questionnaire, and adjustments were made only after evaluating the results of the present pilot study.

The original Swedish questionnaire was developed and pilot-tested with the target population of cancer-bereaved parents, which is recommended (Charlton 2000). Other studies show that a questionnaire targeted to a specific population is perceived as meaningful to fill out (Alderman and Salem 2010; Omerov et al. 2013). In a review (Maneesriwongul and Dixon 2004, p. 183), the authors found there is no consensus among researchers about a "single perfect translation technique". They suggest using multiple approaches when translating a questionnaire. The recommendations of the WHO (Retrieved January 5, 2018), Wild et al. (2005), and Sperber (2004) were used as guidelines for the translation process and linguistic validation of the questionnaire in the present study. There are some discrepancies between the recommendations of these three guidelines. The WHO (Retrieved January $5,2018)$ recommends one forward and one backward translation, whereas both Sperber and Wild (Sperber 2004; Wild et al. 2005) recommend two independent forward and backward translations. The present study used two independent forward translators and two independent back-ward translators. This made it possible to compare the translations for discrepancies in the phrasing of the questions or response alternatives. However, the problems that the informants had with understanding certain words (e.g., cancer or relapse, Table 2) were not discovered during the translation process, which indicates the necessity of cognitive probing with the target population as well. In this study, cognitive probing was conducted in interviews, as recommended (WHO, Retrieved January 5, 2018; Wild et al. 2005). The cognitive probing was found to be important as it resulted in small but important changes in the questionnaire that improved the phrasing of the questions and response alternatives and thus targeted the population of Norwegian cancer-bereaved parents.

The WHO guidelines also recommend that questionnaires avoid wordings or phrases that the target population may find offensive (Retrieved January 5, 2018). The parents in this study had the strongest negative reaction to the response alternative "Yes, completely" to the question asking whether they had worked through their grief. Three of the parents in these interviews claimed that it was not possible to completely work through the grief of losing a child. For one informant, this 
response alternative evoked negative emotions, such as anger and resentment; therefore, that response alternative was removed. The findings in the present pilot study diverge somewhat from those of a study that used the original Swedish version of the questionnaire. In that study, 11\% of participating Swedish parents indicated that they had worked through their grief completely (Kreicbergs et al. 2007).

\subsection{Questions Added}

The health-care systems in Nordic countries are largely comparable in their ideology, structure, and economy (they are financed to a great extent by taxes), with only small differences in the community health-care systems (Kristiansen and Pedersen 2000). Therefore, it was not expected that this study would find any differences in perceived health-care between Swedish and Norwegian bereaved parents. However, the Swedish study-specific questionnaire contains only a single item asking the parents whether they are satisfied with the follow-up after they lost their child. In this study, however, the parents said there were not enough items in the questionnaire addressing the subject of follow-up; so questions on this topic were added (Table 2). The findings of this pilot study about the importance of follow-up in the local community were consistent with the findings of other studies of bereaved parents; parents have emphasized the need for support after the loss of a child (Omerov et al. 2013; Robert et al. 2012; Logan et al. 2017), including follow-up from health-care professionals who treated their child (Barrera et al. 2009; Kreicbergs et al. 2007). In fact, if physicians do not have any contact with the parents after the loss, then the parents can feel abandoned (Lichtental et al. 2015). In Norway, follow-up might face challenges due to problems with interactions between specialist- and community health-care services. Communication between these organizations may be delayed, insufficient, or absent, and doctors in hospitals may fail to convey information to the patients' general practitioners (GP) (Rapport fra Helsetilsynet 2016). In response to this problem, the Norwegian government introduced the Coordination Reform (White Paper nr. 47 2009). This White Paper stresses the need for coordinated health-care services. It gives municipalities more responsibilities around health-care services, including follow-up. Ensuring the best possible follow-up requires that health-care professionals at the hospital where the child died inform the parent's GP about the child's death, and that the GP contacts the parents to inquire about their needs for follow-up. In the question that as added to the Norwegian study-specific questionnaire about follow-up in the home community, parents can indicate who followed-up with them, and whether the follow-up was efficient and add personal comments.

There are several questions about social support in this study-specific questionnaire. These questions address support from health-care professionals, family, relatives, and friends during the child's illness period. In addition, there is a response alternative "Other" as an option where the parents themselves can identify who they perceived to receive social support from (e.g., a co-workers or social workers).

\subsection{Vulnerable Population}

Parents whose child has a life-threatening disease or who have lost their child are considered as a vulnerable group (Kreicbergs et al. 2004; Stevens et al. 2010). Bereaved parents may suffer from negative outcomes, such as anxiety, depression (Kreicbergs 2004), mental illness (Li et al. 2005), increased risk of mortality (Li et al. 2003), sadness, hopelessness, pain, (Hogan and Schmidt 2002), low resilience, or anxiety (Rubin and Malkinson 2001). Two impediments to researching vulnerable populations are recruiting (Stevens et al. 2010; UyBico et al. 2007) and retaining (Akard et al. 2014) eligible participants. These problems were illustrated in the initial recruitment for the present study; at first, only one parent out of twelve invited gave a written consent to participate, and after the second round of invitations, another parent withdrew consent after receiving the questionnaire. A paradox to the problem of recruitment for bereavement studies is that previous studies have found that most bereaved parents consider it valuable to participate and report positive outcomes and only a few indicate that participation affected them negatively (Kreicbergs et al. 2004). Even though it is painful to tell the story of their bereavement, parents report that participation in such studies is beneficial 
and positive (Dyregrov 2004). These findings align with those of the present pilot study, in which all parents who completed the interviews indicated that participation was a positive experience for them; none of the participants in this study indicated that it affected them negatively.

Even though the participating parents were informed that their identify would not be disclosed, they were reluctant to reveal information about their age, gender, or specifics of their child's age, gender, and type of cancer. Their main reason for this was that Norway is a small country, and only a few children die of cancer each year, so providing such information might disclose their identity. Since the main goal of the interviews was to ensure the quality of the translation, it was decided to exclude sociodemographic data from this article.

Initially, the researchers intended to meet with the informants for face-to-face interviews, which is considered as the "gold standard" in qualitative research (McCoyd and Kerson 2006, p. 389). However, studies of vulnerable populations have found that telephone interviews can cause less emotional distress (Trier-Bieniek 2012). Telephone interviews facilitate in-depth discussions with members of a vulnerable population, which should be "considered primary rather than additional approach for qualitative study" (Mealer and Jones 2014, p. 37). In the present study, the first informant requested a telephone interview, due to the sensitive topic and direct phrasing of the questions. Since telephone interviews are time- and cost-effective, the remaining interviews were conducted by telephone as well. This decision was also made to ensure a comparable procedure for all informants. Previous studies have found that telephone interviews can be used to obtain adequate information (Da Silva et al. 2014; Del Duca et al. 2013; Zhang et al. 2017). However, telephone interviews also have some disadvantages: They do not allow for non-verbal communication or interaction between the informant and researcher (Trier-Bieniek 2012), and telephone informants may be less cooperative and less interested in the survey (Holbrook et al. 2003).

\section{Implications for Practice}

Losing a child to cancer disrupts the family situation. Parents are at risk of developing severe psychological and physical illnesses. A questionnaire that addresses the health-care provided to children with cancer and their families can give information about the parents' needs and what they consider to be important during their child's illness and following the loss. Since social support and professional counselling are helpful for most bereaved parents, it is important to understand what kinds of social resources the parents find helpful and whether they need formal or informal social support the most. Health-care professionals depend on the information acquired from parents and the sick children's families to provide excellent health-care in the future. Information from the parents will make it possible to tailor interventions for such parents and families in the future.

\section{Strengths and Limitations}

A strength of the present pilot study is that all the participants were cancer-bereaved parents and thus reflect the target population of the Norwegian national survey to be conducted. A limitation is that five of the six parents participating were recruited from the Norwegian Children's Cancer Society, which might have caused a rather homogenous group and therefore may not be representative of all cancer-bereaved parents. To our knowledge, the guidelines for translation and linguistic validation of questionnaires were developed for scales measuring a concept rather than a questionnaire addressing a range of topics. Therefore, the linguistic validation of this study-specific questionnaire were cognitively tested in a less strictly form than the guidelines for a scale translated from e.g., English to French, which might be a further limitation of this study. Another limitation is only six participants were included in this pilot study, and this number was too small for cognitive testing. In addition, fathers were underrepresented, and there was a lack of ethnic and racial variety in this population. These limitations should be addressed in future research with a more representative population. 


\section{Conclusions}

Since parents who lose a child to cancer are at risk of developing physical and psychological illnesses, it is important to gather information from this bereaved group about their positive and negative experiences during their child's illness and following the loss of their child. The studyspecific questionnaire that was developed in Sweden was based on bereaved parents' experiences and therefore targets this population. Parents' positive and negative experiences can provide the knowledge to implement appropriate interventions to promote health and well-being among cancer-bereaved parents.

Even though Sweden and Norway are geographically close and have quite similar languages and cultures, the interviews indicated the need for some minor revisions after the translation of the study-specific questionnaire. The findings from our interviews emphasize the need for a thorough assessment of questionnaires that are translated from one language to another, even if the source and target cultures and languages are similar. The changes were made to improve the precision and comprehensibility of the questions and the response alternatives for the Norwegian parents.

Author Contributions: Conceptualisation: H.-K.V., M.-E.B.E., T.Ra.; Formal analysis: H.-K.V., T.Ra., M.-E.B.E., T.Re., A.E.W., U.K.M.; Funding Acquisition: T.Ra., M.-E.B.E., U.K.M.; Investigation: H.-K.V.; Methodology: H.-K.V.; Project administration: H.-K.V.; Supervision: T.Ra., M.-E.B.E., A.E.W., T.Re., U.K.M.; Validation: H.-K.V., T.Ra., M.-E.B.E., T.Re., U.K.M., A.E.W.; Visualization: H.-K.V.; Writing Original Draft Preparation: H.-K.V.; Writing—reviewing and editing: M.-E.B.E., T.Ra., T.Re., A.E.W., U.K.M.

Funding: This study is funded by The Research Council of Norway, grant number 238331, "Health PromotionWorthwhile? Reorienting the Community Health Care Services", by NTNU Norwegian University of Science and Technology, and The Norwegian Children's Cancer Society.

Acknowledgments: The authors thank the bereaved parents who agreed to participate for their willingness to share their experiences. We would also thank Geir Arild Espenes as leader of the project, Ulrika Kreicbergs as the project leader for the Swedish project among cancer-bereaved parents, and research assistant Inger Lise Hansen.

Conflicts of Interest: The authors declare no conflict of interest.

\section{References}

Akard, Terrah Foster, Mary Jo Gilmer, Katy Miller, Amii Corbisiero Steele, Kelly Hancock, Maru Barrera, Bruce Compas, Betty Davies, Mary S. Dietrich, Diane L. Fairclough, and et al. 2014. Factors affecting recruitment and participation of bereaved parents and siblings in grief research. Progress in Palliative Care 22: 75-79. [CrossRef] [PubMed]

Alderman, Amy K., and Barbara Salem. 2010. Survey research. Plastic and Reconstructive Surgery 126: 1381-89. [CrossRef] [PubMed]

Barrera, Maru, Norma Mammone D'Agostino, Gerald Schneiderman, Susan Tallett, Lynlee Spencer, and Vesna Jovcevska. 2007. Patterns of Parental Bereavement Following the Loss of a Child and Related Factors. Omega (Westport) 55: 145-67. [CrossRef] [PubMed]

Barrera, Maru, Kathleen O'Connor, Norma Mammone D'Agostino, Lynlee Spencer, David Nicholas, Vesna Jovcevska, Susan Tallett, and Gerald Schneiderman. 2009. Early parental adjustment and bereavement after childhood cancer death. Death Studies 33: 497-520. [CrossRef] [PubMed]

Beaton, Dorcas E., Claire Bombardier, Francis Guillemin, and Marcos B. Ferraz. 2000. Guidelines for the process of cross-cultural adaptation of self-report measures. Spine 25: 3186-91. [CrossRef] [PubMed]

Bice, Thomas E., and Esko Kalimo. 1971. Comparisons of health-related attitudes: A cross-national, factor analytic study. Social Science and Medicine 5: 283-318. [CrossRef]

Björk, Maria, Annelie J. Sundler, Inger Hallström, and Kina Hammarlund. 2016. Like being covered in a wet and dark blanket-Parents' lived experiences of losing a child to cancer. European Journal of Oncology Nursing 25: 40-45. [CrossRef] [PubMed]

Bogensperger, Julia, and Brigitte Lueger-Schuster. 2014. Losing a child: Finding meaning in bereavement. European Journal of Psychotraumatology 5: 1-9. [CrossRef] [PubMed]

Bricout, Vèronique-Aurèlie. 2017. Translation and linguistic validation of an English version of the Questionnaire of Fatigue for Sport Children "QFSC". Physiology \& Behavior 171: 55-60. 
Buyukcan-Tetik, Asuman, Catrin Finkenauer, Henk Schut, Margaret Stroebe, and Wolfgang Stroebe. 2017. The impact of bereaved parents' perceived grief similarity on relationship satisfaction. Journal of Family Psychology 31: 409-19. [CrossRef] [PubMed]

Charlton, Rodger. 2000. Research: Is an "ideal" questionnaire possible? International Journal of Clinical Practice 54: 356-59. [PubMed]

Da Silva, Guilherme F., Maria Tereza A. Morano, Maria Penha U. Sales, Natalia B. Olegário, Antonio George M. Cavalcante, and Eanes D. B. Pereira. 2014. Comparison of face-to-face interview and telephone interview administration of COPD assessment test: A randomized study. Quality of Life Research: An International Journal of Quality of Life Aspects of Treatment, Care and Rehabilitation 23: 1193-97. [CrossRef] [PubMed]

Dahlen, Aina Helen, Eva Widing, Bernward Zeller, Stein Aaserud, Solveig Hansen, Hilde Koch Lie, Finn Wesenberg, Liv Marit Dørum, and Lena Holmström. 2015. Årsrapport 2015 [Annual report 2015]. Available online: https:/ / www.kreftregisteret.no/globalassets/publikasjoner-og-rapporter/arsrapporter/ publisert-2016/arsrapport-2015-barnekreft.pdf (accessed on 16 November 2017).

Del Duca, Giovani Firpo, Markus Vinicius Nahas, Diego Augusto Santos Silva, Pedro Curi Hallal, Deborah Carvalho Malta, and Marco Aurèlio Peres. 2013. Physical activity indicators in adults from a state capital in the South of Brazil: A comparison between telephone and face-to-face surveys. Cardernos de Saude Publica 29: 2119-29. [CrossRef]

Dyregrov, Kari. 2004. Bereaved parents' experience of research participation. Social Science and Medicine 58: 391-400. [CrossRef]

Eremenco, Sonya L., David Cella, and Benjamin J. Arnold. 2005. A Comprehensive Method for the Translation and Cross-Cultural Validation of Health Status Questionnaires. Evaluation \& the Health Professions 28: 212-32.

Gatta, Gemma, Laura Botta, Silvia Rossi, Tiiu Aareleid, Magdalena Bielska-Lasota, Jacqueline Clavel, Nadya Dimitrova, Zsuzsanna Jakab, Peter Kaatsch, Brigitte Lacour, and et al. 2014. Childhood cancer survival in Europe 1999-2007: Results of EUROCARE-5-a population-based study. The Lancet Oncology 15: 35-47. [CrossRef]

Goodenough, Belinda, Donna Drew, Susan Higgins, and Susan Trethewie. 2004. Bereavement outcomes for parents who lose a child to cancer: Are place of death and sex of parent associated with differences in psychological functioning? Psycho-Oncology 13: 779-91. [CrossRef] [PubMed]

U.S. Department of Health and Human Services Food and Drug Administration. 2009. Guidance for Industry: Patient-Reported Outcome Measures: Use in Medical Product Development to Support Labeling Claims; Silver Spring: Silver spring Publishing.

Hogan, Nancy S., and Lee A. Schmidt. 2002. Testing the grief to personal growth model using structural equation modeling. Death Studies 26: 615-34. [CrossRef] [PubMed]

Holbrook, Allyson L., Melanie C. Green, and Jon A. Krosnick. 2003. Telephone versus Face-to-Face Interviewing of National Probability Samples with Long Questionnaires. Public Opinion Quarterly 67: 79-125. [CrossRef]

Hunt, Hayley, Unnur Valdimarsdottir, Lorelei Mucci, Ulrika Kreicbergs, and Gunnar Steineck. 2006. When death appears best for the child with severe malignancy: A nationwide parental follow-up. Palliative Medicine 20: 567-77. [CrossRef] [PubMed]

Jalmsell, Li. 2015. Towards Good Palliation for Children with Cancer. Recognizing the Family and the Value of Communication. Uppsala, Sweden: Uppsala Universitet.

Kamm, Sherrie, and Brian Vandenberg. 2001. Grief communication, grief reactions and marital satisfaction in bereaved parents. Death Studies 25: 569-82. [CrossRef] [PubMed]

Kreicbergs, Ulrika. 2004. To Lose a Child to Cancer. A Nationwide Study of Parental Experiences. Stockholm: Karolinska Institutet.

Kreicbergs, Ulrika, Unnur Valdimarsdóttir, Erik Onelöv, Jan-Inge Henter, and Gunnar Steineck. 2004. Anxiety and depression in parents 4-9 years after the loss of a child owing to a malignancy: A population-based follow-up. Psychological Medicine 34: 1431-41. [CrossRef] [PubMed]

Kreicbergs, Ulrika, Unnur Valdimarsdóttir, Gunnar Steineck, and Jan-Inge Henter. 2004. A population-based nationwide study of parents' perceptions of a questionnaire on their child's death due to cancer. Lancet 364: 787-89. [CrossRef]

Kreicbergs, Ulrika, Unnur Valdimarsdóttir, Erik Onelöv, Olle Björk, Gunnar Steineck, and Jan-Inge Henter. 2005. Care-related distress: A nationwide study of parents who lost their child to cancer. Journal of Clinical Oncology 23: 9162-71. [CrossRef] [PubMed] 
Kreicbergs, Ulrika C., Patrizia Lannen, Erik Onelov, and Joanne Wolfe. 2007. Parental grief after losing a child to cancer: Impact of professional and social support on long-term outcomes. Journal of Clinical Oncology 25: 3307-12. [CrossRef] [PubMed]

Kristiansen, Ivar Sønbø, and Kjeld Møller Pedersen. 2000. Helsevesenet i de nordiske land—Er likhetene større enn ulikhetene? Tidsskrift for Den Norske Legeforening 17: 2023-29.

Lannen, Patrizia. 2008. The Experience of Parents Who Have Lost a Child to Cancer: Palliative and Bereavement Care. Bern: University of Bern.

Lannen, Patrizia K., Joanne Wolfe, Holly G. Prigerson, Erik Onelov, and Ulrika C. Kreicbergs. 2008. Unresolved grief in a national sample of bereaved parents: Impaired mental and physical health 4 to 9 years later. Journal of Clinical Oncology 26: 5870-76. [CrossRef] [PubMed]

Li, Jiong, Dorthe Hansen Precht, Preben Bo Mortensen, and Jørn Olsen. 2003. Mortality in parents after death of a child in Denmark: A nationwide follow-up study. Lancet 361: 363-67. [CrossRef]

Li, Jiong, Thomas Munk Laursen, Dorthe Hansen Precht, Jørn Olsen, and Preben Bo Mortensen. 2005. Hospitalization for Mental Illness among Parents after the Death of a Child. New England Journal of Medicine 352: 1190-96. [CrossRef] [PubMed]

Lichtental, Wendy G., Corinne R. Sweeney, Kailey E. Roberts, Geoffrey W. Corner, Leigh A. Donovan, Holly G. Prigerson, and Lori Wiener. 2015. Bereavement Follow-Up after the Death of a Child as a Standard of Care in Pediatric Oncology. Pediatric Blood Cancer 62: 834-69. [CrossRef] [PubMed]

Lichtenthal, Wendy G., Geoffrey W. Corner, Corinne R. Sweeney, Lori Wiener, Kailey E. Roberts, Raymond E. Baser, Yuelin Li, William Breitbart, David W. Kissane, and Holly G. Prigerson. 2015. Mental health services for parents who lost a child to cancer: If we build them, Will they come? Journal of Clinical Oncology 33: 2246-53. [CrossRef] [PubMed]

Logan, Emma L., Jennifer A. Thornton, Robert T. Kane, and Lauren J. Breen. 2017. Social support following bereavement: The role of beliefs, expectations, and support intentions. Death Studies 1187: 34. [CrossRef] [PubMed]

Maneesriwongul, Wantana, and Jane K. Dixon. 2004. Instrument translation process: A methods review. Journal of Advanced Nursing 48: 175-86. [CrossRef] [PubMed]

McCarthy, Maria C., Naomi E. Clarke, Cheng Lin Ting, Rowena Conroy, Vicki A. Anderson, and John A. Heath. 2010. Prevalence and predictors of parental grief and depression after the death of a child from cancer. Journal of Palliative Medicine 13: 1321-26. [CrossRef] [PubMed]

McCoyd, Judith L.M., and Toba Schwaber Kerson. 2006. Conducting Intensive Interviews Using Email. Qualitative Social Work: Research and Practice 5: 389-406. [CrossRef]

Mealer, Meredith, and Jacqueline Jones. 2014. Methodological and ethical issues related to qualitative telephone interviews on sensitive topics. Nurse Researcher 21: 32-37. [CrossRef] [PubMed]

Meert, Kathleen L. M., Sherylyn H. Briller, Stephanie Myers Schim, Celia Thurston, and Allison Kabel. 2009. Examining the needs of bereaved parents in the pediatric intensive care unit: A qualitative study. Death Studies 33: 712-40. [CrossRef] [PubMed]

Monterosso, Leanne, and Linda J. Kristjanson. 2008. Supportive and palliative care needs of families of children who die from cancer: An Australian study. Palliative Medicine 22: 59-69. [CrossRef] [PubMed]

Murphy, Shirley A., Janet Lohan, Tom Braun, Clark L. Johnson, Kevin C. Cain, Randal D. Beaton, and Robert Baugher. 1999. Parents' health, health care utilization, and health behaviors following the violent deaths of their 12- to 28-year-old children: A prospective longitudinal analysis. Death Studies 23: 589-616. [PubMed]

Najman, Jake M., John C. Vance, Fran Boyle, Gary Embleton, Bill Foster, and John Thearle. 1993. The impact of a child death on marital adjustment. SosialScience EMedicine 37: 1005-10.

Olsen, Jørgen H., Torgil Möller, Harald Anderson, Frøydis Langmark, Risto Sankila, Laufey Tryggvadóttír, Jeanette Falck Winther, Catherine Rechnitzer, Gudmundur Jonmundsson, Jane Christensen, and et al. 2009. Lifelong cancer incidence in 47697 patients treated for childhood cancer in the nordic countries. Journal of the National Cancer Institute 101: 806-13. [CrossRef] [PubMed]

Omerov, Pernilla, Gunnar Steineck, Bo Runeson, Anna Christensson, Ulrika Kreicbergs, Rossana Pettersén, Birgitta Rubenson, Johanna Skoogh, Ingela Rådestad, and Ullakarin Nyberg. 2013. Preparatory studies to a population-based survey of suicide-bereaved parents in Sweden. Crisis 34: 200-10. [CrossRef] [PubMed] 
Quittner, Alexandra L., Sheri Sweeny, Marc Watrous, Paul Munzenberger, Karen Bearss, Amy Gibson Nitza, Lisa A. Fisher, and Bernadette Henry. 2000. Translation and linguistic validation of a disease-specific quality of life measure for cystic fibrosis. Journal of Pediatric Psychology 25: 403-14. [CrossRef] [PubMed]

Rapport fra Helsetilsynet. 2016. Informasjonen var mangelfull og kom ofte for sent. Oppsummering av landsomfattende tilsyn i 2015 med samhandling om utskriving av pasienter fra spesialisthelsetjenesten til kommunen. Oslo: Helsetilsynet, Available online: https:/ / www.helsetilsynet.no/publikasjoner/rapport-fra-helsetilsynet / 2016/informasjonen-var-mangelfull-og-kom-ofte-for-sent-oppsummering-av-landsomfattande-tilsyn-i2015/ (accessed on 25 November 2017).

Robert, Rhonda, Donna S. Zhukovsky, Riza Mauricio, Katherine Gilmore, Shirley Morrison, and Guadalupe R. Palos. 2012. Bereaved Parents' Perspectives on Pediatric Palliative Care. Journal of Social Work in End-Of-Life $\mathcal{E}$ Palliative Care 8: 316-38.

Rubin, Simon Shimshon, and Ruth Malkinson. 2001. Parental response to child loss across the life cycle: Clinical and research perspectives. In Handbook of Bereavement Research: Consequences, Coping, and Care. Edited by Margaret S. Stroebe, Wolfgang Stroebe, Robert O. Hansson and Henk Schut. Washington, DC: American Psychological Association, pp. 219-40.

Siegel, Rebecca L., Kimberly D. Miller, and Ahmedin Jemal. 2018. Cancer Statistics, 2018. CA. A Cancer Journal for Clinicians 68: 7-30. [CrossRef] [PubMed]

Song, Jieun, Frank J. Floyd, Marsha Mailick Seltzer, Jan S. Greenberg, and Jinkuk Hong. 2010. Long-Term Effects of Child Death on Parents' Health-Related Quality of Life: A Dyadic Analysis. Family Relations 59: 269-82. [CrossRef] [PubMed]

Sperber, Ami D. 2004. Translation and validation of study instruments for cross-cultural research. Gastroenterology 126: S124-28. [CrossRef] [PubMed]

Sperber, Ami D., Robert F. Devellis, and Brian Boehlecke. 1994. Cross-Cultural Translation: Methodology and Validation. Journal of Cross-Cultural Psychology 25: 501-24. [CrossRef]

Stevens, Michael M., Bruce A. Lord, Marie-Thèrèse Proctor, Sue Nagy, and Elizabeth O'Riordan. 2010. Research with Vulnerable Families Caring for Children with Life-Limiting Conditions. Qualitative Health Research 20: 496-505. [CrossRef] [PubMed]

Stroebe, Margaret, Henk Schut, and Wolfgang Stroebe. 2007. Health outcomes of bereavement. The Lancet 370: 1960-73. [CrossRef]

Surkan, Pamela J. 2006. Predictors and Consequences of Loss of a Child: Nationalwide Epidemiological Studies from Sweden. Stockholm: Karolinska Instutuet.

Surkan, Pamela J., Ulrika Kreicbergs, Unnur Valdimarsdóttir, Ullakarin Nyberg, Erik Onelöv, Paul W. Dickman, and Gunnar Steineck. 2006. Perceptions of Inadequate Health Care and Feelings of Guilt in Parents after the Death of a Child to a Malignancy: A Population-Based Long-Term Follow-Up. Journal of Palliative Medicine 9: 317-31. [CrossRef] [PubMed]

Trier-Bieniek, Adrienne. 2012. Framing the telephone interview as a participant-centred tool for qualitative research: A methodological discussion. Qualitative Research 12: 630-44. [CrossRef]

UyBico, Stacy J., Shani Pavel, and Cary P. Gross. 2007. Recruiting vulnerable populations into research: A systematic review of recruitment interventions. Journal of General Internal Medicine 22: 852-63. [CrossRef] [PubMed]

Valdimarsdóttir, Unnur, Ulrika Kreicbergs, Arna Hauksdóttir, Hayley Hunt, Erik Onelöv, Jan-Inge Henter, and Gunnar Steineck. 2007. Parents' intellectual and emotional awareness of their child's impending death to cancer: A population-based long-term follow-up study. Lancet Oncology 8: 706-14. [CrossRef]

Van der Geest, Ivana M. M., Anne-Sophie E. Darlington, Isabelle C. Streng, Erna M. C. Michiels, Rob Pieters, and Marry M. van den Heuvel-Eibrink. 2014. Parents' Experiences of Pediatric Palliative Care and the Impact on Long-Term Parental Grief. Journal of Pain and Symptom Management 47: 1043-53. [CrossRef] [PubMed]

Weidner, Norbert. J., Marcella Cameron, Rebecca C. Lee, Judy McBride, Emily J. Mathias, and Terry L. Byczkowski. 2011. End-of-life care for the dying child: What matters most to parents. Journal of Palliative Care 27: 279-86. [PubMed]

Wender, Esther. 2012. Supporting the family after the death of a child. Pediatrics 130: 1164-69. [CrossRef] [PubMed] 
White Paper nr. 47. 2009. The Coordination Reform, Proper Treatment-At the Right Place and Right Time. Oslo: Norwegian Ministry of Health and Care Services. Available online: https://www.regjeringen.no/ contentassets /d4f0e16ad32e4bbd8d8ab5c21445a5dc/no/pdfs/stm200820090047000dddpdfs.pdf (accessed on 16 December 2017).

WHO. n.d. Process of Translation and Adaptation of Instruments. Available online: http://www.who.int/ substance_abuse/research_tools/translation/en/ (accessed on 5 January 2018).

Wild, Diane, Alyson Grove, Mona Martin, Sonya Eremenco, Sandra McElroy, Aneesa Verjee-Lorenz, and Pennifer Erikson. 2005. Principles of good practice for the translation and cultural adaptation process for patient-reported outcomes (PRO) measures: Report of the ISPOR Task Force for Translation and Cultural Adaptation. Value in Health 8: 94-104. [CrossRef] [PubMed]

Zhang, XiaoChi, Lars Kuchinke, Marcella L. Woud, Julia Velten, and Jürgen Margraf. 2017. Survey method matters: Online/offline questionnaires and face-to-face or telephone interviews differ. Computers in Human Behavior 71: 172-80. [CrossRef]

(C) 2018 by the authors. Licensee MDPI, Basel, Switzerland. This article is an open access article distributed under the terms and conditions of the Creative Commons Attribution (CC BY) license (http://creativecommons.org/licenses/by/4.0/). 